\title{
Heavy Metal Pollution Assessment by Partial Geochemical Extraction Technique
}

\section{Samuel Estifanos}

Department of Earth Science, CNCS, P.O. Box 231, Mekelle University, Mekelle, Ethiopia (sambersih@yahoo.com)

\begin{abstract}
$\mathrm{Mn}$ and Fe oxides are powerful absorbents of heavy metal cations in soils and stream sediments therefore considered in this environmental geochemical investigation. Steam sediment samples were collected from $\mathrm{Au}-\mathrm{Ag}$ and $\mathrm{Pb}-\mathrm{Zn}-\mathrm{Cu}$ mineralized areas of the Rodalquilar old gold mine, located in the southeastern part of Spain. Total and partial chemical analyses were done, using aquaregia and hydroxylamine-hydrochloric acid solutions, respectively to examine preferential concentration of $\mathrm{Zn}, \mathrm{Pb}$ and $\mathrm{Cu}$ in amorphous and ore mineral phases. The results show scavenging association of $\mathrm{Pb}, \mathrm{Zn}$ and $\mathrm{Cu}$ with $\mathrm{Mn}$ that is shown by their concentrations in amorphous phases as detected by partial extractions,
\end{abstract}

Key words: Partial and total extraction, Amorphous phase, Scavenging, Heavy metal pollutants.

\section{INTRODUCTION}

Normally heavy metals are not harmful to our environment because they are only present in very small amounts. The environmental pollution concern rises when they show up in higher concentration due to natural mineralizing processes and/or human activities. The heavy metals threatening the ecosystem include mercury, arsenic, copper, barium, cadmium, antimony, chromium, lead and zinc. The effects caused by heavy metals vary in that dissolved copper can affect lower trophic levels such as phytoplankton while lead, cadmium and mercury become accumulated through the food-chain, posing a toxic risk to species higher in the food chain, and eventually to humans. The degree of fixation of trace elements by $\mathrm{Mn}$ and Fe oxides ranges from adsorption at the surface, through co-precipitation, to relatively strong binding within the oxide structure (Hall, 1997).

Dissolution techniques of samples prior to chemical analysis can be classified as partial extraction and sequential (selective) multiple extraction (Fig. 1). The basic assumption of sequential extraction is that the reagents used are able to dissolve one mineral phase, selectively without solubilizing the others. Partial extraction involves dissolution of all mineral phases which requires milder reagents. The use of partial extraction techniques in the enhancement of soil and stream sediments geochemical anomalies has been applied with success in temperate and Mediterranean climates for $\mathrm{Cu}, \mathrm{Zn}, \mathrm{Pb}$ and $\mathrm{U}$ (Cardoso and Ferreira, 1998). Partial and sequential (selective) 
extractions have been adopted in studies related to both exploration geochemistry and environmental geochemistry (Cornu et al., 2002; Kelley et al., 2003; Rodrigues and Formoso, 2005; Nada et al., 2011). The requirements of sample decomposition in environmental geochemistry are less exacting than those in exploration works because minerals that require rigorous conditions to be solubilized are unlikely to have environmental impact.

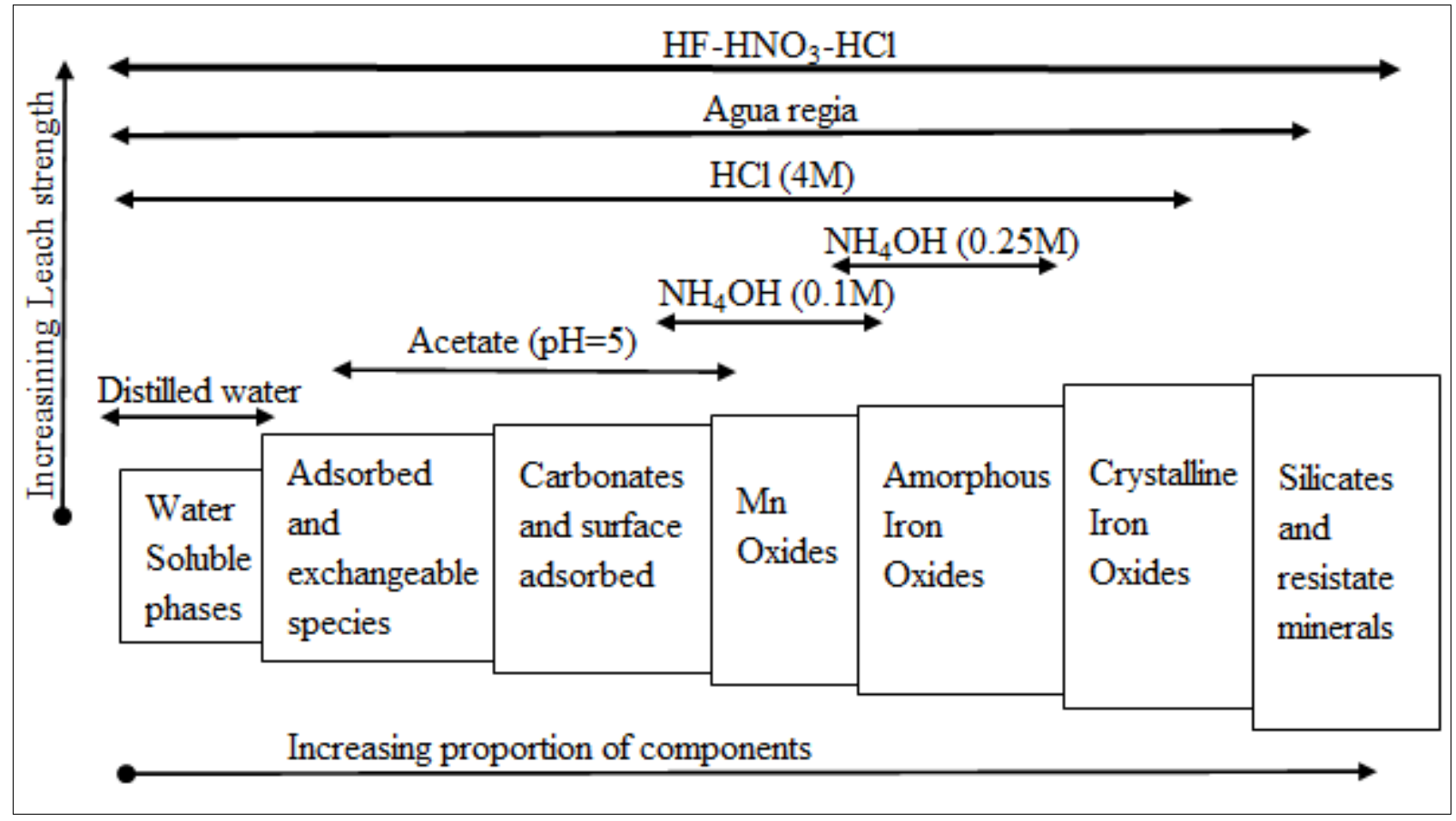

Figure 1. Relationship of leachant type (reagent for total, partial and selective leaching) and component leached in a sample (Modified after Cohen et al., 2007).

The degree with which the potentially toxic metals impact the ecosystem depends on their solubility in solutions of varying $\mathrm{pH}$ conditions. This is in turn related to the phases of occurrence of the metals. A toxic heavy metal is said to have the highest impact on the ecosystem when it exists in a mineral form that dissolves easily with water; otherwise, it has the lowest impact when the host mineral needs rigorous acidic conditions to dissolve, a rare case in nature such as acid mine drainage (AMD). Thus, based on the analytical results, the scavenging degree of the three potentially toxic metals $(\mathrm{Pb}, \mathrm{Cu}$ and $\mathrm{Zn})$ by $\mathrm{Mn}$ and $\mathrm{Fe}$ on the study area is assessed.

Manganese is not found as a free metal in nature, however its minerals consisting of oxides, silicates and carbonates are the most common (Web Elements, 2005). The iron and steel industry and acid mine drainage release a large portion of manganese found in the environment. Manganese is very similar to iron in its chemical behavior and so is frequently found in association with iron 
(Eugene, 2000). Mn is essential micronutrient with certain limit. The maximum contamination level (MCL) drinking water standard is $50 \mathrm{ppb}$ (Table 1).

$\mathrm{Cu}$ is essential nutrient but excesses can be toxic and it is essentially immobile under basic $\mathrm{pH}$ conditions. $\mathrm{Zn}$ is essentially immobile under basic $\mathrm{pH}>5$ and remains sorbed to clay and free oxides in upper layer of the soil. lead is non-essential and toxic heavy metal(Siegel, 2002).

Table 1.Summary of the heavy metals (HM) abundances in the continental crust (UCCA), maximum contamination levels (MCL) and lower limits of detection (LDL) by ICP-AES* technique (after Siegel, 2002)

\begin{tabular}{|ccccc|}
\hline $\begin{array}{c}\text { S. } \\
\text { No }\end{array}$ & $\boldsymbol{H M}$ & $\begin{array}{c}\text { UCCA } \\
\text { (ppm except Fe(\%)) }\end{array}$ & $\begin{array}{c}\text { MCL } \\
\text { in water }(\boldsymbol{p p b})\end{array}$ & $\begin{array}{c}\text { LDLfor ICP- } \\
\text { AES }(\text { ppb })\end{array}$ \\
\hline 4 & $\mathrm{~Pb}$ & 20 & 1.5 & 10 \\
\hline 5 & $\mathrm{Zn}$ & 71 & 5000 & 4 \\
\hline 6 & $\mathrm{Cu}$ & 25 & 1000 & 4 \\
\hline 7 & $\mathrm{Fe}$ & 3.5 & 200 & \\
\hline 8 & $\mathrm{Mn}$ & 600 & 50 & \\
\hline
\end{tabular}

*ICP-AES: Inductively Coupled Plasma- Atomic Emission Spectrometer.

Several workers have developed a method for the selective dissolution of manganese oxides from soils and sediments. This method uses a solution of $0.1 \mathrm{M}$ hydroxylamine $\left(\mathrm{NH}_{4} \mathrm{OH}\right)$ and hydrochloride in $0.01 \mathrm{M} \mathrm{HNO}_{3}$ at $\mathrm{pH}=2$ (Thompson, 1983). The action of the hydroxylamine hydrochloride solution under the above conditions is specific to manganese oxides (Fig. 1). Crystalline iron oxides such as goethite, hematite and magnetite do not dissolve in this solution (Cardoso and Ferreira, 1998).Selective extraction of Mn oxides and Fe oxides is usually performed by using reagents, hydroxylamine hydrochloride being the popular choice (Hall, 1997).

The aim of this paper is to examine the significance of selective and total extraction techniques in dissolving $\mathrm{Mn}$ and $\mathrm{Fe}$ mineral phases and assess heavy metals pollution in the mineral phases. These techniques are used to investigate how trace elements are distributed between the phases. Moreover, these extractions have been used in the past for geochemical exploration because it has been perceived that elements associated with mineralization (especially those hosted by sulfides) are more likely to be released during weathering than those in barren rocks (hosted by silicates), more widely dispersed, and more probably held by secondary minerals and hence likely to be preferentially released by extraction solutions. In contrast, some of the new extraction techniques 
Samuel, E (MEJS)

Volume 5 (1):71-88, 2013

currently used for geochemical exploration are partial rather than selective digests, i.e. they extract part of a phase or phases, rather than a selected mineral (Gray, 1996).

\section{MATERIALS AND METHODS}

\subsection{Study area}

The Study area is located in the South-eastern part of Spain (Fig. 2A). The approximate total catchment area considered is about $18 \mathrm{Km}^{2}$. Extensive mining workings and ore processing wastes have caused exposure of sulfide rocks to the atmosphere and loading of waste sediments to the stream systems eventually reaching the Sea.

A number of studies have previously been conducted in the study area with aspects ranging from pure exploration geological to environmental pollution studies as well as remote sensing applications (Arribas et al., 1995; Wray, 1998; Ferrier, 1999; Chica-Olmo et al., 2001; Estifanos, 2006). The gold-alunite deposits are located in the central part of the volcanic field within the Rodalquilar caldera complex where four volcanic complexes are identified. The volcanogenic complexes are overlain by younger fossilized calcareous limestone (Arribas et al., 1995) (Fig. 2B).

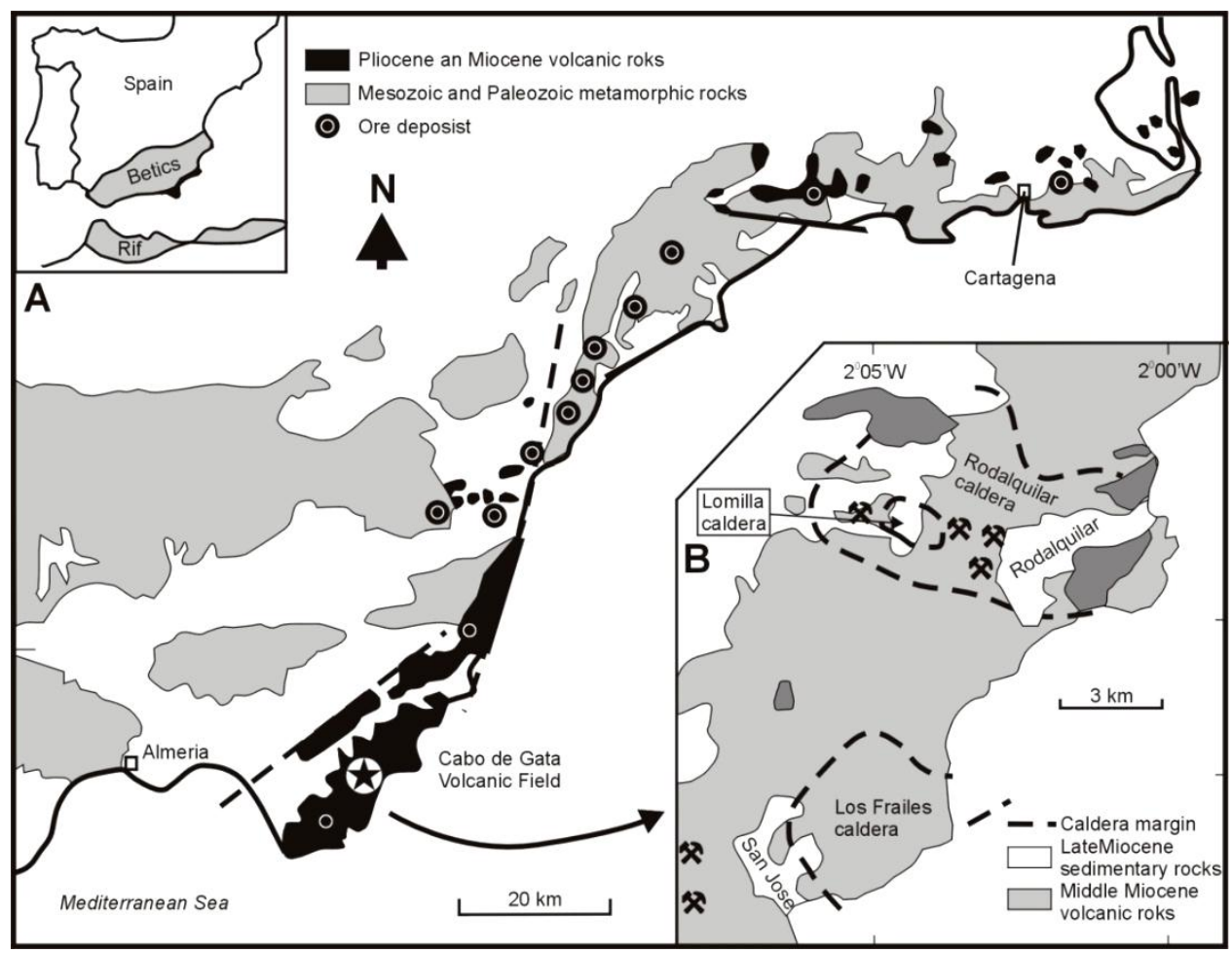

Figure 2. Showing (A) location and regional geology and (B) local geology (After Arribas et al., 1995). 
Samuel, E (MEJS)

Volume 5 (1):71-88, 2013

\subsection{Sampling and geochemical analysis}

Stream sediment samples were collected in June, 2005, at the junctions of tributaries in the lower and higher orders of the main stream beds of the Rodalquilar area (Fig. 3). At each sample point five to seven central scoops of the dry sediments were collected from the stream bed using a stainless steel and was sieved with a $<1 \mathrm{~mm}$ stainless steel sieve. All sampling equipments were thoroughly cleaned between each sampling spot to avoid sample-to-sample contamination. Blank and standard samples as well as 5 duplicate sample analyses were made to check the quality of the analysis of ICP- AES. The results of these controlling samples indicate that the quality of the analysis was very good.

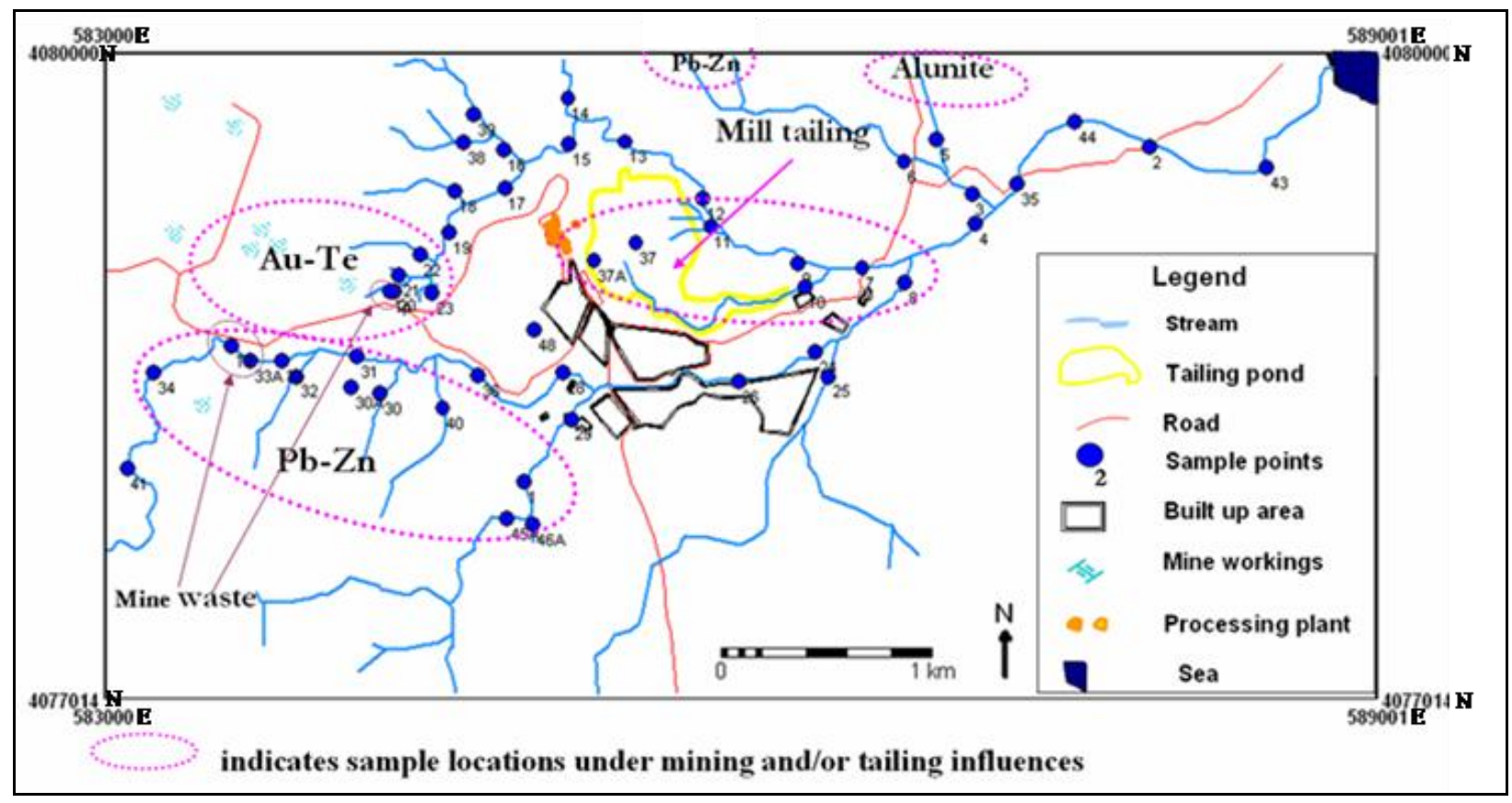

Figure 3. Spatial distribution of stream sediment samples in the study area (coordinates in UTM).

The samples were subjected to geochemical analysis in International Institute for Geo-information

Science and Earth Observation (ITC) geochemical laboratory where ICP-AES analytical instrument was used. A number of elements were extracted from three solutions: water, hydroxylamine (partial extraction) and aqua regia (total extraction) following the procedures described in table 2.

$10 \mathrm{gm}$ of each sample was dissolved in water and shaken for some time. ICP-AES could detect cations of $\mathrm{Fe}, \mathrm{Mn}, \mathrm{Pb}, \mathrm{Zn}, \mathrm{Cu}, \mathrm{Ca}, \mathrm{Mg}$ and $\mathrm{Na}$ being dissolved for concentration above the detection limit. Whereas the major ions in water can be determined directly, the background levels 
of most heavy metals, including $\mathrm{Cu}, \mathrm{Pb}, \mathrm{Zn}$ and $\mathrm{Cd}$ are too low for direct determination even by ICP (Thompson, 1983).

For partial extraction, $1 \mathrm{gm}$ of each sample was digested in $20 \mathrm{ml}$ solution of $0.25 \mathrm{M}$ hydroxylamine and $0.1 \mathrm{~mol}$ hydrochloric acid before $\mathrm{Mn}, \mathrm{Cu}$, and $\mathrm{Zn}, \mathrm{Pb}$ were analyzed by ICP-AES. The partial geochemical extraction was aimed to extract the pollutants that might have been attached to amorphous phases of Mn and Fe minerals.

In total extraction, a solution of aqua regia (3:1 ratio of hydrochloric and nitric acids), is used to dissolve a wide range of mineral phases releasing cations of heavy metals from crystalline phases. Aqua regia has similar extraction characteristics to nitric acid - perchloric acid but the former is more effective in dissolving some sulfides notably pyrite (Thompson, 1983). A 1:4 mixture of perchloric and nitric acid if slowly evaporated to dryness with $0.25 \mathrm{gm}$ samples of rock, soil or sediment, provides powerful decomposition of the greater part of any heavy metals present (Thompson, 1983). The elements to be determined satisfactorily are $\mathrm{Cu}, \mathrm{Pb}, \mathrm{Zn}, \mathrm{Cd} \mathrm{Mn}, \mathrm{Fe}, \mathrm{Co}$, Ni, Mo and P (Thompson, 1983).

Table 2. Geochemical analytical procedure for the three leachates.

\begin{tabular}{|c|c|c|}
\hline Water extraction $(W)$ & Partial extraction (HA) & Total extraction (AR) \\
\hline $10 \mathrm{gm}$, & $1 \mathrm{gm}$ & $1 \mathrm{gm}$ \\
\hline $\begin{array}{l}\text { Adding } 25 \mathrm{ml} \text { demineralized } \\
\text { water }\end{array}$ & $\begin{array}{l}20 \mathrm{ml} \text { of } 0.25 \mathrm{M} \text { hydroxylamine } \\
\text { and } 0.1 \mathrm{M} \mathrm{HCl} \text { solution }\end{array}$ & $\begin{array}{l}5 \mathrm{ml} \text { agua regia and } 5 \mathrm{ml} \\
\text { demineralized water }\end{array}$ \\
\hline Shaking for 2 hours & Shaking for two hrs in $60^{\circ} \mathrm{C}$ water & Shaking for $4 \mathrm{hrs}$ in $70^{\circ} \mathrm{C}$ water \\
\hline Settling for half an hour & Settling for half an hour & Settling for half an hour \\
\hline \multicolumn{3}{|l|}{$\mathrm{pH}$ measurement } \\
\hline Decantation & Decantation & Decantation \\
\hline Centrifuging $4000 \mathrm{rpm}$ & Centrifugal 4000rpm & \\
\hline Settlement and decantation & Settlement and decantation & \\
\hline Filtering over a funnel & Filtering over a funnel & Filtering over a funnel \\
\hline \multicolumn{3}{|c|}{$\begin{array}{l}\text { Storage in a } 20 \mathrm{ml} \text { Pyrex test } \begin{array}{l}\text { Storage in a } 20 \mathrm{ml} \text { pyrex test tube } \\
\text { tube with stopper }\end{array} \\
\text { with stopper }\end{array}$} \\
\hline & & $\begin{array}{l}\text { Diluting for } 100 \mathrm{ml} \mathrm{de} \text {-ionized } \\
\text { water }\end{array}$ \\
\hline $\begin{array}{l}\text { ICP AES analyses for } \mathrm{Fe}, \\
\mathrm{Mn}, \mathrm{Zn}, \mathrm{Pb}, \mathrm{Cu}\end{array}$ & $\begin{array}{l}\text { ICP AES analyses for } \mathrm{Fe}, \mathrm{Mn}, \mathrm{Zn} \text {, } \\
\mathrm{Pb}, \mathrm{Cu}, \mathrm{Pb}\end{array}$ & $\begin{array}{l}\text { ICP AES analyses for } \mathrm{Fe}, \mathrm{Mn} \text {, } \\
\mathrm{Sb}, \mathrm{Cu}, \mathrm{Pb}, \mathrm{Zn}\end{array}$ \\
\hline
\end{tabular}




\subsection{Statistical analysis}

The geochemical analysis dataset from both the total and partial extraction were treated in such a way that the cations concentration from the crystalline and amorphous phases of the sample materials is separated. This is done simply by subtracting the cations concentration in the partial extraction from that of total extraction to separate the cations that were in crystalline phases and considering the difference between partial and water extraction for cations in amorphous phases.

\section{RESULTS AND DISCUSSION}

\subsection{Distribution of $\mathrm{Mn}, \mathrm{Zn}, \mathrm{Pb}$ and $\mathrm{Cu}$ in the three phases}

The partial geochemical extraction conducted using $20 \mathrm{ml}$ of $0.25 \mathrm{M}$ hydroxylamine and $0.1 \mathrm{M} \mathrm{HCl}$ solution was aimed to extract the contaminants that might have been attached to amorphous phases of minerals. Unlike, sequential extraction which can selectively dissolve particular phase, the partial extraction includes the water soluble mineral phases also. To enhance the heavy metals concentration attached to amorphous and crystalline/primary rocks, the difference between partial and water extractable values (HA - W) as well as difference between total and partial extraction values (AR - HA) were considered respectively.

Among zinc, copper and lead detected in water, partial and total extractions (Table3), lead exceeds the MCL of $1.5 \mathrm{ppb}$ even in the water extractable concentration level (Fig. 4). It is widely accepted that the water extractable metal in sediments is more mobile, highly toxic and the most bioavailable fraction (Lalita and Srilert, 2011).Moreover, its average concentration from partial extraction accounts about $50 \%$ of the total extraction. The average concentration of the total extraction values of these heavy metals exceed their crustal abundances (Fig. 5)

Table3. Statistical summary for the geochemical parameters in three extraction datasets.

\begin{tabular}{|l|c|r|r|r|r|}
\hline \multicolumn{6}{|c|}{ Water extractable: Descriptive Statistics } \\
\hline & $\mathrm{N}$ & Min. & Max. & Mean & Std. Dev. \\
\hline Fe ppm & 50 & 0.03 & 732 & 26 & 104.35 \\
\hline Mn ppm & 50 & 0.01 & 105 & 2.56 & 14.75 \\
\hline Cu ppm & 50 & 0 & 29 & 0.79 & 4.09 \\
\hline Pb ppm & 50 & 0.07 & 1 & 0.28 & 0.18 \\
\hline Zn ppm & 50 & 0.01 & 40 & 1.02 & 5.60 \\
\hline
\end{tabular}

\begin{tabular}{|l|r|r|r|r|r|}
\hline \multicolumn{6}{|c|}{ Partial-extraction: Descriptive Statistics } \\
\hline & $\mathrm{N}$ & Min. & Max. & Mean & Std. Dev. \\
\hline Fe ppm & 50 & 220 & 3000 & 965.00 & 539.92 \\
\hline Mn ppm & 50 & 18 & 4504 & 773.28 & 988.40 \\
\hline Cu ppm & 50 & 5 & 238 & 40.44 & 49.80 \\
\hline Pb ppm & 50 & 3 & 9318 & 418.62 & 1465.26 \\
\hline Zn ppm & 50 & 4 & 255 & 59.08 & 57.00 \\
\hline
\end{tabular}

\begin{tabular}{|l|r|r|r|r|r|}
\hline \multicolumn{6}{|c|}{ Total-extraction: Descriptive Statistics } \\
\hline & N & Min. & Max. & Mean & Std. Dev. \\
\hline Fe \% & 50 & 2 & 6 & 3.46 & 0.71 \\
\hline Mn ppm & 50 & 61 & 6353 & 1033.08 & 1243.56 \\
\hline Cu ppm & 50 & 35 & 585 & 120.75 & 124.07 \\
\hline Pb ppm & 50 & 31 & 18811 & 930.38 & 2930.38 \\
\hline Zn ppm & 50 & 28 & 728 & 193.28 & 152.52 \\
\hline
\end{tabular}

$\mathrm{Mn}$ and $\mathrm{Fe}$ are considered in this paper to verify their scavenging property towards the heavy metals. Mn exceeds the MCL set to be $50 \mathrm{ppb}$ in its water extractable phases while MCL of $0.2 \mathrm{ppm}$ 
is set for Fe which is claimed to be potentially toxic and thus it is in polluting level in at least the water extractable phase in the study (Table 3).

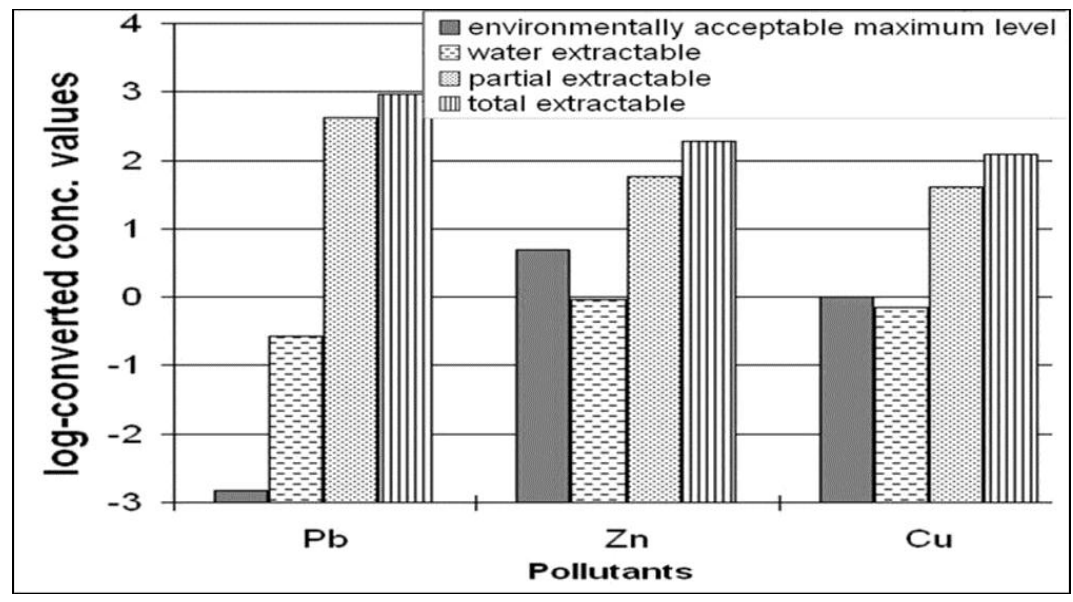

Figure 4. Histogram showing the elevated concentration of heavy metals $(\mathrm{Pb}, \mathrm{Zn}$ and $\mathrm{Cu})$ relative to environmentally acceptable level (the values are plotted on log scale to enhance the low values of the environmentally accepted limits for relative comparison purpose)

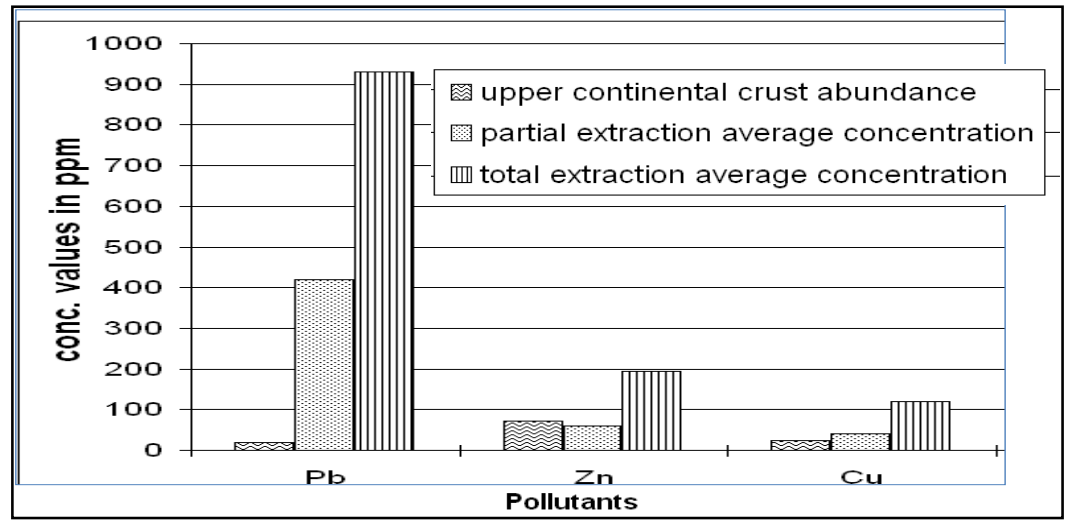

Figure 5. Histogram showing comparison of average concentration of pollutants with upper crustal abundance

The following pie diagrams illustrate the approximate and relative proportion of the contaminants in the three broad phases (Fig. 6). The pie diagrams show that $\mathrm{Fe}-\mathrm{Zn}-\mathrm{Cu}-\mathrm{Pb}-\mathrm{Mn}$ cations are attached to amorphous phase (HA-W) in increasing order. The higher proportion of $\mathrm{Mn}$ in the amorphous phase indicates the presence of Mn minerals predominantly as either amorphousminerals or coating material since the partial extraction is known to be efficient in dissolving amorphous Mn-related minerals. A number of studies strengthen that $\mathrm{Mn}$ minerals have scavenging affinity towards a number of heavy metals (Hall, 1997;Kuang-Chung et al., 2001; O’Reilly, 2002; Wenfeng et al., 2005). 

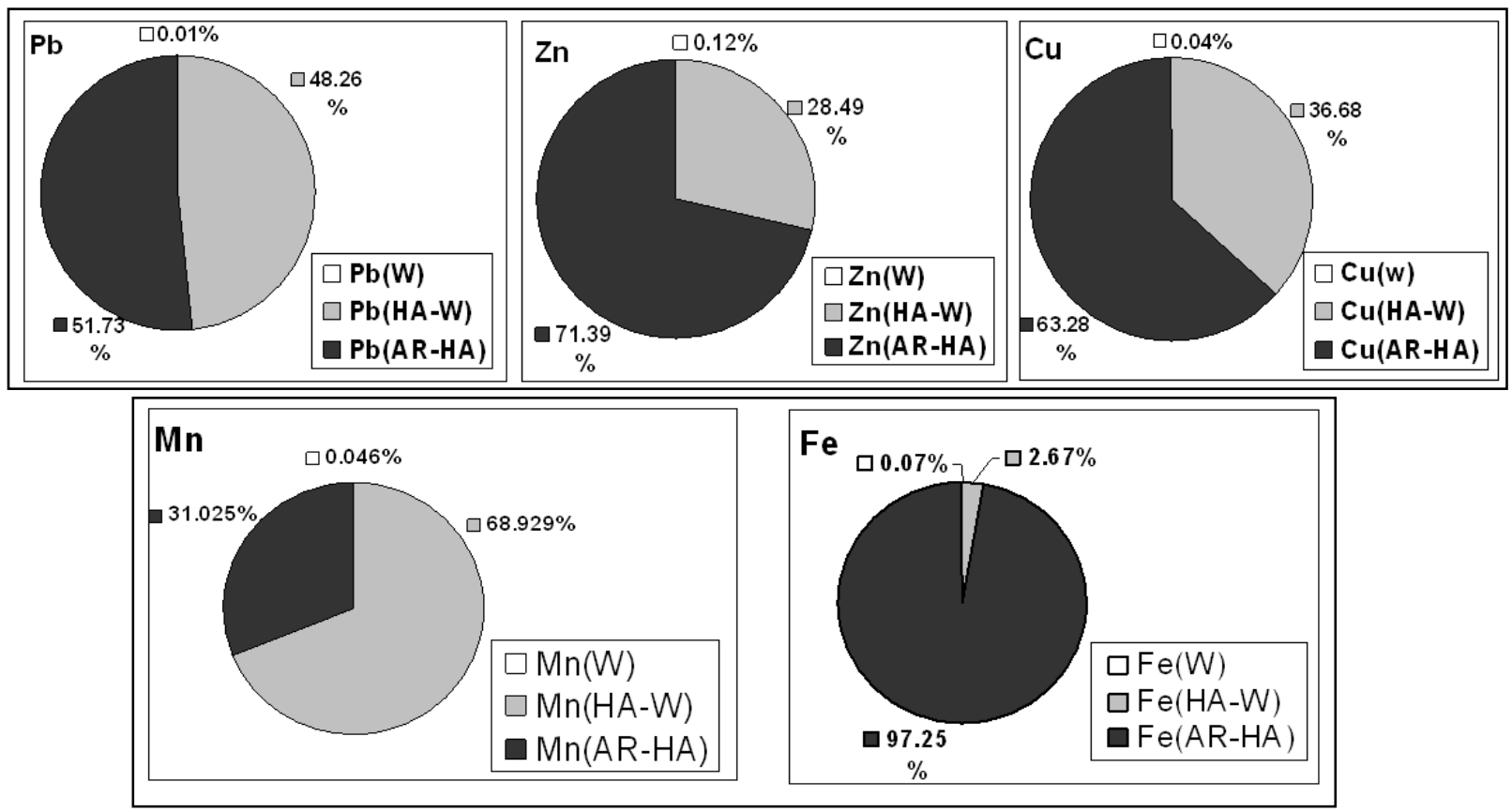

Figure 6. Pie diagrams showing relative proportions of $\mathrm{Pb}, \mathrm{Zn}, \mathrm{Cu}, \mathrm{Fe}$ and $\mathrm{Mn}$ Cations in the three phases (W: water extractable, HA-W: amorphous and AR-HA: crystalline phases).

Manganese (III/IV) oxides/hydroxides are common in soils and sediments as particles and coatings on mineral surfaces (Russell, 1998). Manganese is known to be the most important scavenger for many inorganic cations such as $\mathrm{Cu}, \mathrm{Pb}, \mathrm{Zn}, \mathrm{Co}$ and $\mathrm{Ni}$ among others. This is because it exists in several oxidation states forming non-stoichometric oxides with different valences. Its higher valence oxides exist in several crystalline forms that co-precipitate and solid solution with $\mathrm{Fe}$ oxides. It can have surface areas of several hundred $\mathrm{m}^{2} / \mathrm{g}$ and larger CEC (cation exchange capacity) than some clay minerals, though they are much less abundant than iron oxides (Hall, 1997; O'Reilly, 2002). However, the metal's mobilities are expected to be affected also by the prevailing natural $\mathrm{pH}$ conditions of the area.

\subsection{Spatial Patterns of the Pollutants}

The spatial association of the heavy metals with manganese was assessed using plots. The partial extraction values were subtracted from the total extraction concentration values to determine the portion contained in the crystalline phases of each trace elements: $\mathrm{Mn}, \mathrm{Pb}, \mathrm{Cu}$ and $\mathrm{Zn}$. In the spatial assessment, the proportion of the amorphous phases relative to the crystalline phases of the trace elements is considered. The plots in figure7 show the spatial variability of both manganese and the other heavy metals and evaluate the scavenging relationships in the amorphous phases. 


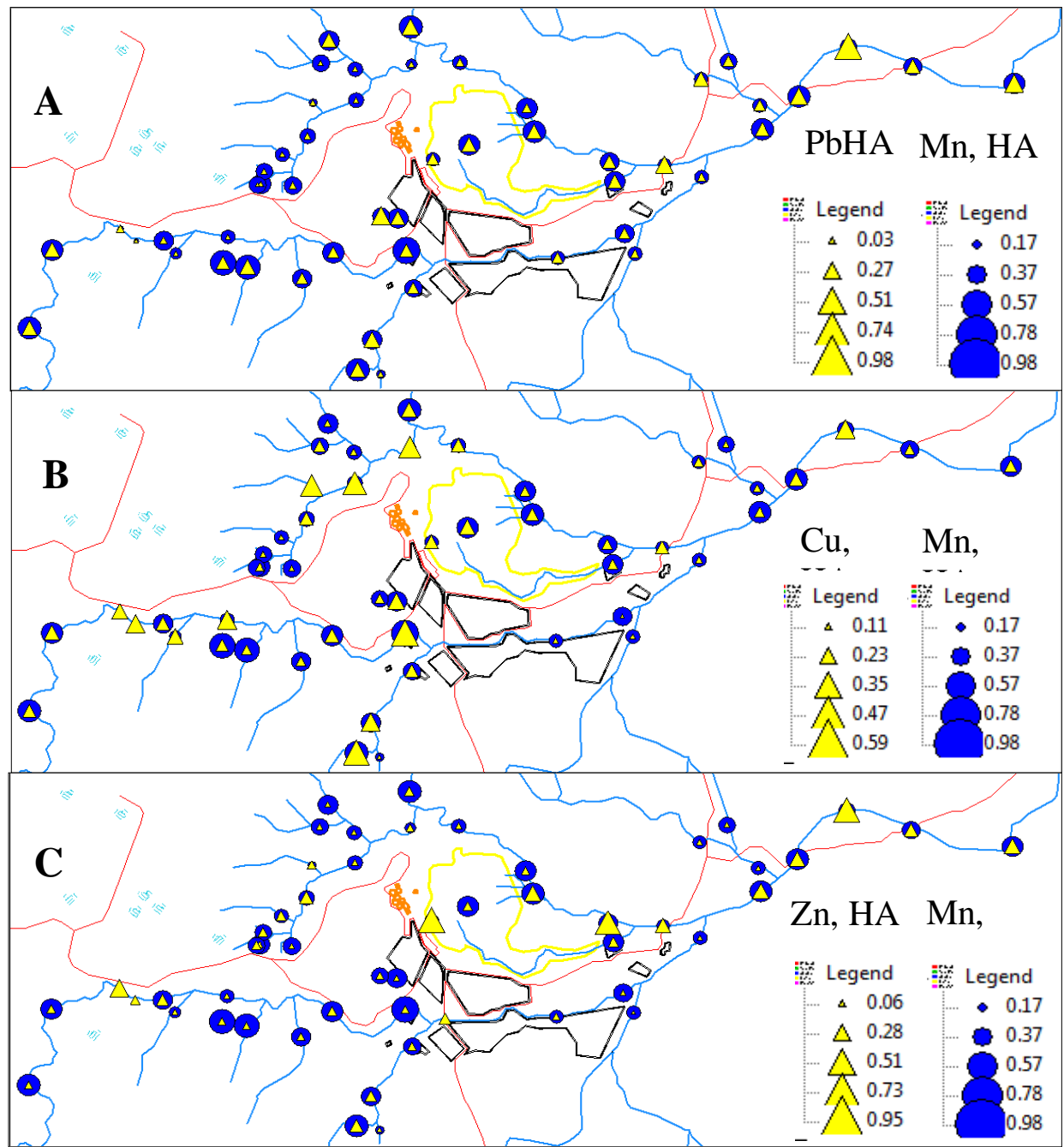

Figure 7. Plots of the partial extraction values in proportion to total extraction values $(\mathrm{A} . \mathrm{Pb}$ vs $\mathrm{Mn}$; B. $\mathrm{Cu}$ vs $\mathrm{Mn}$ and C. $\mathrm{Zn}$ vs $\mathrm{Mn}$ ).

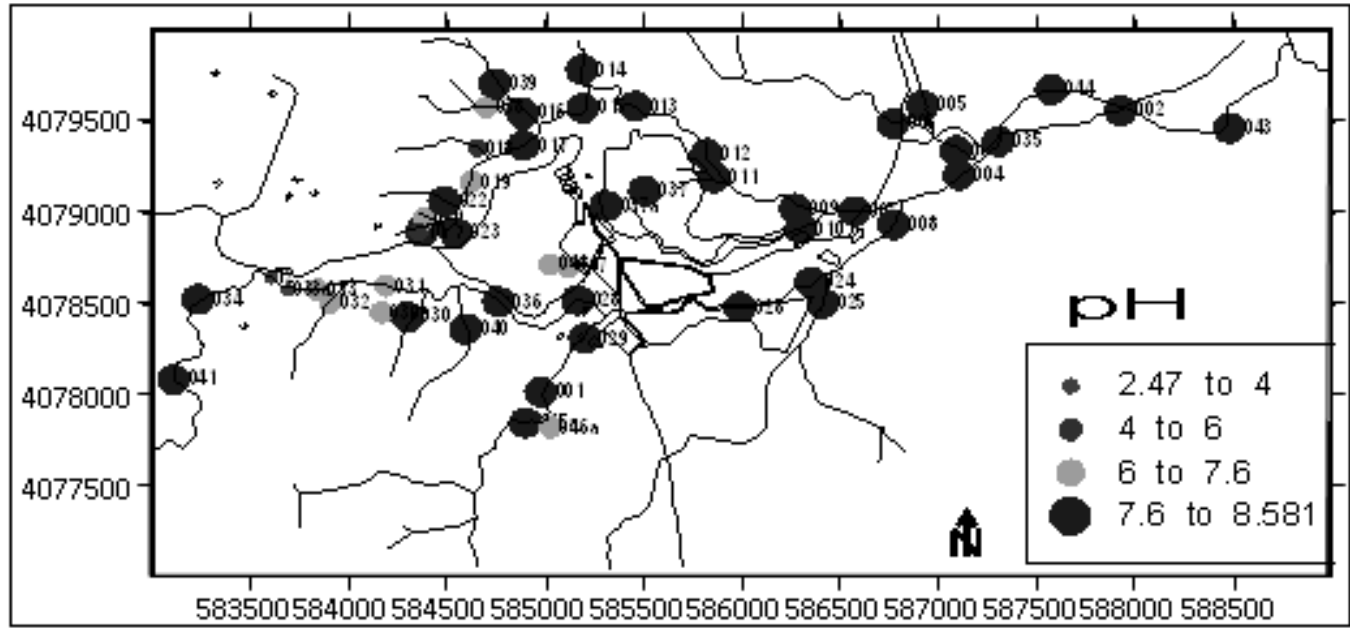

Figure 8. Spatial pattern of $\mathrm{pH}$ values in the study area. 
In the plots, it is evident that Mn has spatial association with lead (Fig. 7A), with copper (Fig. 7B) and with zinc (Fig. 7C) in decreasing order. The proportion of the trace metals in their amorphous phases is significantly higher in the downstream part and show consistent correlation with Mn amorphous proportions. This indicates the scavenging effect of Mn on the heavy metals whose ore minerals could also have undergone physical and chemical weathering in the course of transport downstream (Nair and Ramachandran, 2002). The inconsistencies of the relationship between Mn and the three heavy metals in some of the samples is attributed to the possible formation of their amorphous phases by virtue of other metal accumulation mechanisms than scavenging by $\mathrm{Mn}$ minerals (Xiangdong et al., 2001). Such processes can also include weathering of the ore minerals and/or co-precipitation of the heavy metals in the stream sediment transport (Elza et al., 2012).

The $\mathrm{pH}$ of the stream sediments in general is alkaline (7.6) with few acidic extremes in the mine wastes (Fig. 8). Alkalinity in the mill tailing (ground sulfide materials) can possibly be due to the metallurgical methods practiced to concentrate gold involving cyanide solutions in a medium with $\mathrm{pH} 9$ to 11. There is a general trend of $\mathrm{pH}$ values to increase down stream which implies the dilution effect of more water accumulation in the higher order of streams which experience occasional flux of water due to the arid climate.

\subsection{Down Stream Patterns}

There are two main streams in the study area that drains towards east and joins together before reaching the Mediterranean Sea. Figure 9A shows the two paths from which path-II is selected for assessing the downstream patterns since it experiences $\mathrm{Pb}-\mathrm{Cu}-\mathrm{Zn}$ loading from mineralization at around sample spots 45 and 28. In the following graphs, the peaks at sample spot 28 are due to $\mathrm{Pb}$ $\mathrm{Zn}-\mathrm{Cu}$ loading from the tributary towards sample 45 (Fig. 9B-E).

The comparison is between the concentration values of the heavy metals in their amorphous including water extractable phases (HA) and crystalline phases (AR-HA). These two phases explain the relative proportions of the metals in weathered/ adsorbed and ore minerals portions of the samples respectively.

All the heavy metals except $\mathrm{Cu}$ and $\mathrm{Fe}$ showed lower concentration in the partial extraction values including water extractable values (HA) than their extraction values crystalline phases (AR-HA) in the most downstream part of the study area. Fe exhibit by far lower values in its partial extraction implying that the dominant host mineral is crystalline such as hematite which is the most common ore mineral of Iron (Fig. 9C \& F). This suggests that Fe has lower scavenging role to the heavy 
metals in its amorphous phases. The lower values of copper at down stream can possibly be due to erosion of the amorphous phase to the sea in the form of suspension while the portions in the crystalline phase remain in the stream sediment. This can be supported by the fact that heavy metals are not necessarily attached permanently to stream sediment particles, but they can also be remobilized through chemical, physical and biological processes (Edward et al., 2005; Jelodar et al., 2012).

Copper's partial extraction value exceeds its counterpart, at only sample spot 28 where Mn showed elevated value in its amorphous phase (HA) implying the possible preferential association of copper and manganese in the vicinity including sample spot 36 (Fig. 9C \& E).

$\mathrm{Zn}, \mathrm{Pb}$ and $\mathrm{Mn}$ revealed higher concentration values in their amorphous (HA) than crystalline phases (AR-HA) downstream. It is evident that there is a shift in the prevalence of their mineral phases at sample spot 4 with the predominance of crystalline phases upstream and amorphous phases downstream of this sample spot along the path. This phenomenon can be elaborated by the sediment load from path-1 which covers the catchment area of the old gold mining areas and mill tailings in most upstream down to the sea (Fig. 9A).

\subsection{Statistical correlations}

Four transects were selected to investigate the possible relationships among the three heavy metals (Fig. 10A). Such relationships include co-mineralization (mineral assemblage), adsorption (scavenging) and co-precipitation (weathering). Transect-b is found to be more relevant in the transect-wise correlation of the pollutants $(\mathrm{Pb}, \mathrm{Zn}$ and $\mathrm{Cu})$ and scavengers $(\mathrm{Mn}$ and $\mathrm{Fe})$ followed by transect-c.

Scatter plots reveal the existence of association of $\mathrm{Mn}$ with $\mathrm{Zn}, \mathrm{Cu}$ and $\mathrm{Pb}$ in the modes of comineralization and absorption. To illustrate these findings, the geochemical analysis values of $\mathrm{Mn}$ from the total extraction (AR), the difference between total and partial (AR-HA) as well as values from the partial extraction (HA) are correlated with $\mathrm{Zn}, \mathrm{Cu}$ and $\mathrm{Pb}$ values from the same extraction phases. The relationship among the three heavy metals due to co-mineralization is better explained using the values from (AR-HA) while that due to absorption is better explained using the values from the partial extraction (HA). 

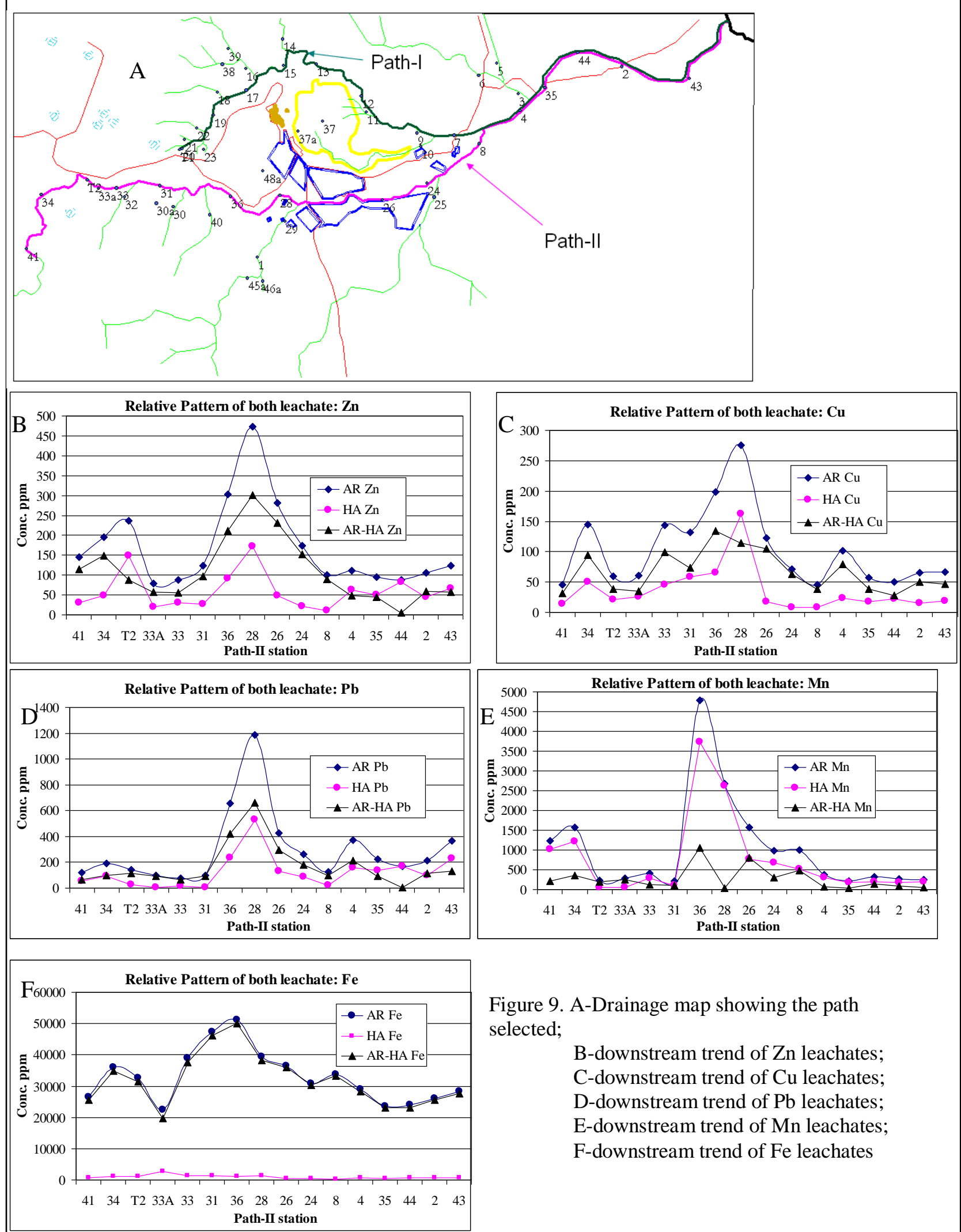

Figure 9. A-Drainage map showing the path selected;

B-downstream trend of $\mathrm{Zn}$ leachates;

$\mathrm{C}$-downstream trend of $\mathrm{Cu}$ leachates;

$\mathrm{D}$-downstream trend of $\mathrm{Pb}$ leachates;

E-downstream trend of Mn leachates;

F-downstream trend of Fe leachates 


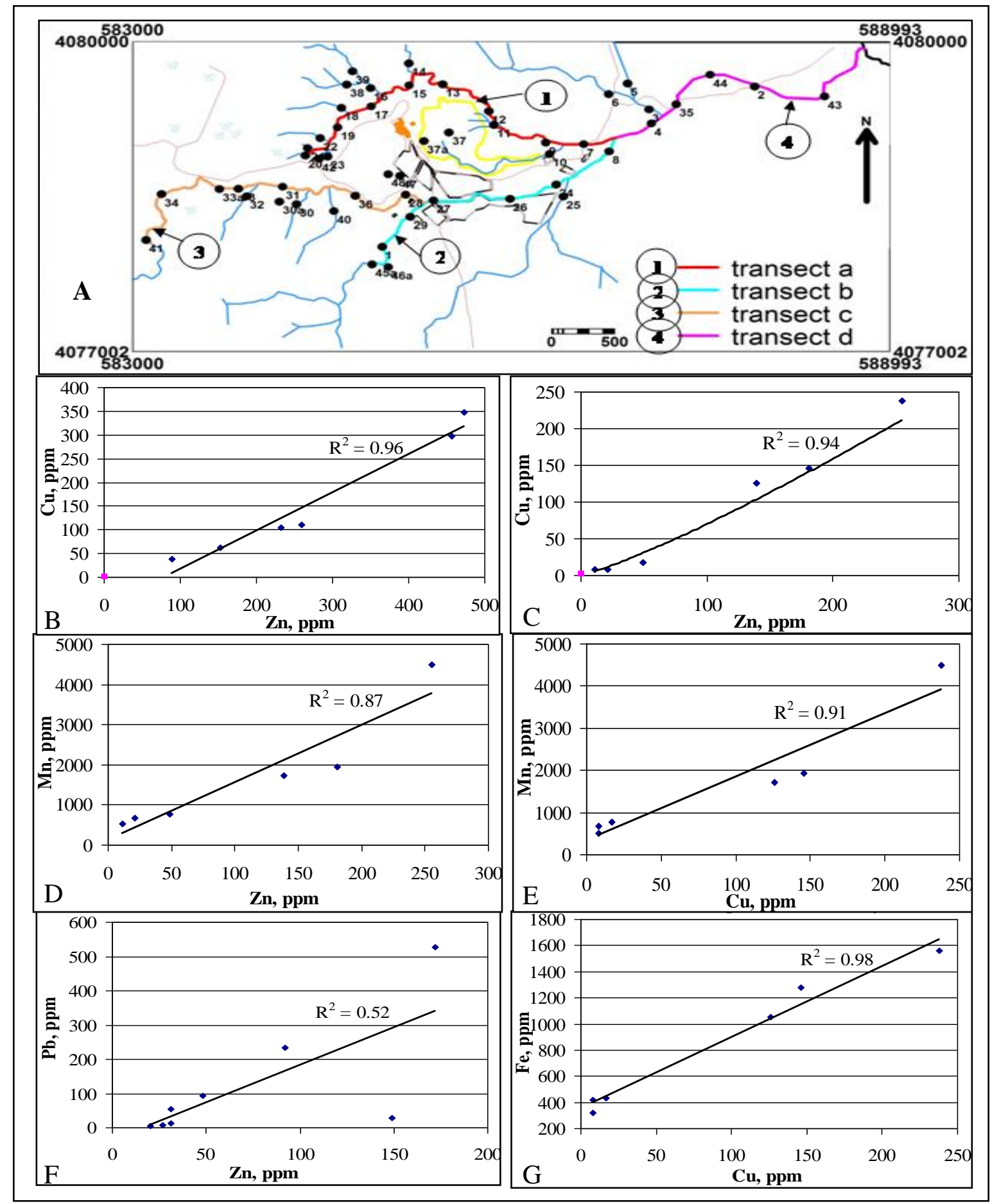

Figure 10.(A) The drainage map of the study area with four transects; Scatter plots;(B) $\mathrm{Zn}$ vs $\mathrm{Cu}$, AR-HA, along transect-b (co-mineralization); (C) $\mathrm{Zn}$ vs $\mathrm{Cu}$, HA, along transect-b (coprecipitation); (D) Zn vs Mn, HA, along transect-b (Adsorption); (E) Cu vs Mn, HA, along transect-b (Adsorption); (F) $\mathrm{Zn}$ vs $\mathrm{Pb}, \mathrm{HA}$, along transect-c (co-precipitation); (G) $\mathrm{Cu}$ vs $\mathrm{Fe}, \mathrm{HA}$, along transect-b (Adsorption). 
Samuel, E (MEJS)

Volume 5 (1):71-88, 2013

Significant correlation between the concentration values of $\mathrm{Zn}$ and $\mathrm{Cu}$ in their crystalline phases (AR-HA) along transect-b is explained by the assemblage of the metals during mineralization in the upstream and consequent transport downstream (Fig. 10B). Association by weathering processes (co-precipitation) among the heavy metals is strong along transect-b as the correlation of the partial extraction values depicted (Fig. 10C).

The relationships among the heavy metals along the other transects than transect-b was found relatively weak with the possibly co-precipitation between $\mathrm{Zn}$ and $\mathrm{Pb}$ along transect-c being the highest (Fig. 10F). The main reason for these weaker correlations can be attributed to weaker degree of $\mathrm{Pb}-\mathrm{Zn}-\mathrm{Cu}$ mineralization and other factors such as the tailing materials, milling processes and local geology.

The scavenging effect of $\mathrm{Mn}$ and Fe has been clearly indicated by their significant correlations with the heavy metal pollutants along transect-b (Fig. 10D, E \& G). In the course of stream sediment transport along transect $b$, amorphous manganese minerals has played adsorption role on the heavy metals when they get free through weathering and/or water dissolution.

\section{CONCLUSION}

This present work has further indicated the potential application of partial extraction techniques in assessing the distribution of heavy metals due to absorption. The absorption affinity of $\mathrm{Mn}$ to $\mathrm{Zn}$ and $\mathrm{Cu}$ has been examined using geochemical data from total and partial extraction values as well as their respective difference. Manganese was found to have stronger scavenging effect on $\mathrm{Cu}$ than on $\mathrm{Zn}$ and $\mathrm{Pb}$ as shown by simple statistical correlations. Iron was found to exit predominantly in its crystalline than amorphous phases.

The partial extraction technique has proved to play great role in heavy metal pollution studies by successfully detaching the heavy metals that might have been scavenged by Mn when transported by stream water or leached out in situ by hypogene soil formations. The three extraction results showed that the area is severely polluted with $\mathrm{Pb}, \mathrm{Cu}$ and $\mathrm{Zn}$ in decreasing order. The partial extraction result is found helpful to investigate the distribution of the heavy metals in amorphous phases by enhancing the scavenging, co-precipitation and co-mineralization pattern of heavy metals. The potential application of partial extraction technique in assessing the distribution of heavy metals spatially as well as in mineral phases has been verified. 
Samuel, E (MEJS)

Volume 5 (1):71-88, 2013

\section{ACKNOWLEDGEMENT}

My heartfelt gratitude is due, to Drs. Boudewijn de Smeth for his devoted assistance and guidance in the laboratory works at ITC geochemical laboratory, the Netherlands whereby the dataset was generated and served in this work for further investigation as extension beyond the scope of my M.Sc thesis. I am highly grateful to Dr. K. Bheemalingeswara and the anonymous reviewers for their important feedbacks that helped much for the initial manuscript to reach its current form.

\section{REFERENCE}

Arribas, A. J.R., Cunningham, C. G., Rytuba, J. J., Rye, R. O., Kelly, W. C., Podwysocki, M. H., McKee, E. H \& Tosdal, R. M. 1995. Geology, Geochronology, Fluid inclusions, and Isotope Geochemistry of the Rodalquilar Gold Alunite Deposit, Spain. Economic Geology, 90: $795-822$.

Cardoso, F.E \& Ferreira da Silva, E. 1998. Application of Selective Extraction Techniques in Metal-Bearing Phases Identification: a South European Case Study. Journal of Geochemical Exploration, 61(1-3): 203-212.

Chica-Olmo, M., Abarca, F \& Rigol, J.P. 2001. Development of a Decision Support System Based on Remote Sensing and GIS Techniques for Gold-Rich Area Identification in SE Spain. International Journal of Remote Sensing, 23(22): 4801-4814.

Cohen, D. R., Kelley, D. L., Anand, R \& Coker, W. B. 2007.Major Advances in Exploration Geochemistry, 1998-2007. In Proceedings of Exploration 07: Fifth Decennial International Conference on Mineral Exploration edited by B. Milkereit, 3-18.

Cornu, S., Deschatrettes, V., Salvador, B. S., Clozel, B \& Hardy, M. 2002. Mechanisms and spatial variability of trace element scavenging by a non polluted planosolic horizon. Symposium no. 28, Paper no. $419.17^{\text {th }}$ WCSS, August 2002, Thailand, 14-21.

Edward, D. B., Ian, R. P \& Darry, W. H. 2005. Geochemical Partitioning of Copper, Lead, and Zinc in Benthic, Estuarine Sediment Profiles. Journal of Environmental Quality, 34:263273.

Elza, K., János, T., Stanislav, F. B., Dario, O., Halka, B \& Ivanka, P. 2012. Geochemical Study of Surface Water and Sediment at the Abandoned Pb-Zn Mining Site at Gyöngyösoroszi, Hungary. Fresenius Environmental Bulletin, Parlar Scientific Publications, 21(5a): 1212 1218. 
Estifanos, S. 2006. Spectral Indicators for Assessing Pollution in the Epithermal Gold Mining Area of Rodalquilar, South East Spain. Msc Thesis, Enschede, ITC, 101 pp.

Eugene, R.W. 2000. Applications of Environmental Chemistry. CRC Press, Boca Raton, 276 p.

Ferrier, G. 1999. Application of Imaging Spectrometer Data in Identifying Environmental Pollution Caused by Mining at Rodaquilar, Spain. Remote Sensing of Environment, 68: $125-137$.

Gray, D.G. 1996. Selective extraction techniques for the recognition of buried mineralization, Curara Well, Western Australia. Report 210R, CSIRO Explor. and Mining, Perth, 72 p.

Hall, G.E.M. 1997. Analytical Perspective on Trace Element Species of Interest in Exploration. Journal of Geochemical Exploration, 61(1-3): 1-19.

Jelodar, A. H., Amini, H. R., Navaiynia, B \& Zazouli, M. A. 2012. Heavy metal ions adsorption by suspended particle and sediment of the Chalus River, Iran. African Journal of Biotechnology, 11(3): 628-634.

Kelly, D. L., Hall, G. E. M., Graham, L. C., Ian, C. H \& Robert, M. M. 2003. The use of partial extraction geochemistry for copper exploration in northern Chile. Geochemistry: Exploration, Environment, Analysis, 3: 85-104.

Kuang-Chung, Y., Li-Jyur, T., Shih-Hsiung, C \& Shien-Tsong, H. 2001. Correlation Analyses on Binding Behaviour of Heavy Metals with Sediment Matrices. Water Res. 35:2417-2428.

Lalita, C \& Srilert, C. 2011. Investigating of heavy metals in different depths of soil tailings from Akara Gold Mine, Thailand using three-steps modified BCR sequential extraction. $2^{\text {nd }}$ International Conference on Environmental Science and Technology, IPCBEE vol.6, ACSIT Press, Singapore.

Nada, S., Henri-Charles, D \& Tayssir, H. 2011. Sequential Extraction and Particle Size Analysis of Heavy Metals in Sediments Dredged from the DeûleCanal, France. The Open Environmental Engineering Journal, 4: 11-17.

Nair, M.N.M \& Ramachandran, K.K. 2002. Textural and trace elemental distribution in sediments of the Beypore estuary (SW coast of India) and adjoining innershelf. Indian Journal of Marine Sciences, 31(4): 295-304.

O’Reilly, S.E. 2002. Lead Sorption Efficiencies of Natural and Synthetic Mn and Fe-oxides. PhD Thesis, Virginia Polytechnic Institute and StateUniversity, Blacksburg, 46p. 
Russell, H. A. 1998. Scavenging of particulate and dissolved lead compounds by coprecipitation with manganese oxyhydroxides. MSc thesis.Virginia Polytechnic Institute and State University, Virginia. 80p.

Rodrigues, M. L. K \& Formoso, M. L. L. 2006. Geochemical Distribution of Selected Heavy Metals in Stream Sediments Affected By Tannery Activities. Water, Air, And Soil Pollution, 169: 167-184.

Siegel, F.R. 2002. Environmental Geochemistry of Potentially Toxic Metals. Springer - Verlag, Berlin. 212p.

Thompson, M. 1983. Analytical Methods in Applied Environmental Geochemistry. Applied Environmental Geochemistry. Academic Press Inc, London, 501p.

Web Elements. 2005. The Periodic Table on the WWW. The University of Sheffield and Webelements Ltd, Mark Winter. http://www.webelements.com

Wenfeng, T., Fan, L., Xionghan, F., Qiaoyun, H \& Xueyuan, L. 2005. Adsorption and redox reactions of heavy metals on Fe-Mn nodules from Chinese soils. Journal of Colloid and Interface Science, 284: 600-605.

Wray, D.S. 1998. The Impact of Unconfined Mine Tailings and Anthropogenic Pollution on a Semi-arid Environment - an initial study of the Rodalquilar mining district, south east Spain. Environmental Geochemistry and Health, 20: 29 - 38

Xiangdong, L., Zhenguo, S., Onyx, W. H. W \& Yok-Sheung, L. 2001. Chemical Forms of Pb, Zn and $\mathrm{Cu}$ in the Sediment Profiles of the Pearl River Estuary. Marine Pollution Bulletin, 42(3): 215-223. 